\title{
Emergence of a high-level cefotaxime-resistant Streptococcus pneumoniae strain in New Zealand
}

\author{
MAGGIE S. BRETT \\ Communicable Disease Group, Institute of Environmental Science \& Research, PO Box 50-348, Porirua, New \\ Zealand
}

\begin{abstract}
An increase in the number of cefotaxime-resistant pneumococci referred for surveillance to a central laboratory in New Zealand occurred in 1997-1998. The MIC of cefotaxime for 113 of 216 cefotaxime-resistant isolates of Streptococcus pneumoniae referred was $\geqslant 4 \mathrm{mg} / \mathrm{L}$. Most of the 113 isolates exhibited the same antibiotic resistance pattern and belonged to serotype 19F. To investigate the genetic relatedness of the isolates, 48 serotype 19F pneumococci with varying susceptibility to cefotaxime were further typed by macro-restriction analysis by use of pulsed-field gel electrophoresis. These results suggested that a multiresistant $19 \mathrm{~F}$ strain of $S$. pneumoniae with high-level cefotaxime resistance had emerged from a pre-existing serotype 19F strain.
\end{abstract}

\section{Introduction}

Streptococcus pneumoniae is a major cause of morbidity and mortality and the emergence and spread of penicillin-resistant and multiresistant strains worldwide has caused great concern [1]. The Institute of Environmental Science and Research has monitored the antibiotic susceptibility of pneumococci isolated from episodes of invasive disease in New Zealand since 1976. A low prevalence of antimicrobial drug resistance was found before 1995 [2], but a significant increase in resistance to penicillin and cefotaxime was observed after 1996 [3].

In addition to continuous surveillance of pneumococci from invasive disease, hospital and community laboratories in New Zealand refer clinical isolates of penicillin-resistant pneumococci to the Institute for surveillance of antibiotic-resistant pneumococci. Through this latter surveillance scheme, 1081 penicillin-resistant pneumococci were referred between 1978 and 1996, of which 17 were also cefotaxime-resistant. There was a marked increase in the number of cefotaxime-resistant pneumococci referred in 1997 and 1998. These included 113 isolates with high-level cefotaxime resistance ( $\mathrm{MIC} \geqslant 4 \mathrm{mg} / \mathrm{L}$ ), most of which belonged to serotype 19F. These strains exhibited varying levels of resistance to cefotaxime and a

Received 28 March 2000; revised version received 28 July 2000; accepted 7 Aug. 2000.

Corresponding author: Dr M.S. Brett (e-mail: maggie. brett@esr.cri.nz). selection have been examined by DNA macro-restriction analysis to ascertain their genetic relatedness.

\section{Materials and methods}

\section{Bacterial isolates}

All cefotaxime-resistant pneumococci referred by 25 hospital and community laboratories in New Zealand in 1997 and 1998 were included in the study. An additional serotype 19F isolate from 1996 was included in the macro-restriction analysis. The isolates were identified by $\alpha$-haemolysis, optochin susceptibility and bile solubility tests. All isolates were stored in glycerol broth at $-70^{\circ} \mathrm{C}$

\section{Antimicrobial susceptibility testing and serotyping}

The Etest (AB Biodisk, Solna, Sweden) was used to determine MICs of penicillin, cefotaxime, erythromycin and co-trimoxazole. The Kirby-Bauer disk diffusion method, interpreted according to the recommendations of the National Committee for Clinical Laboratory Standards (NCCLS) [4] was used to determine the susceptibilities to chloramphenicol, tetracycline and vancomycin. Isolates for which the MIC of cefotaxime was $\geqslant 2 \mathrm{mg} / \mathrm{L}$ were regarded as cefotaxime-resistant; those for which the MIC was $\geqslant 4 \mathrm{mg}$ cefotaxime/L were designated 'high-level resistant'. Serotyping was performed as described previously [2].

\section{DNA macro-restriction analysis}

Forty-seven serotype 19F cefotaxime-resistant isolates 
referred in 1997-1998 and one referred during 1996 were typed by a modification of a published DNA macro-restriction analysis method [5]. After digestion with SmaI (New England Biolabs, Beverly, USA) restriction fragments were separated in an agarose $1 \%$ gel (Seakem GTG, FMC Bioproducts, Rockland, ME, USA) with a CHEF Mapper (BioRad Laboratories, Hercules, CA, USA) and a linear ramp of $5-35 \mathrm{~s}$ at $6 \mathrm{~V} / \mathrm{cm}$ for $22 \mathrm{~h}$. The Sma I profiles were compared visually and arbitrarily designated as a common restriction type if the profiles were identical or showed one-to-three band differences. Isolates showing more than three band differences were designated as other restriction types [6].

\section{Results}

\section{Characteristics of the cefotaxime-resistant pneumococci}

In 1997 and 1998, 216 cefotaxime-resistant pneumococci were referred by 25 laboratories from 15 cities and towns in New Zealand. The main isolation sites included: respiratory tract (119), ear (54) and eye (30). Two isolates were from blood cultures. Details of age were known for 207 isolates: $116(56 \%)$ were from patients aged <16 years, $36(17.4 \%)$ from patients aged 16-59 years and $55(26.6 \%)$ from patients $\geqslant 60$ years old.

Of the 216 isolates, 176 were serogrouped. Serogroup 19 accounted for $146(82.5 \%)$ isolates and $25(14 \%)$ belonged to serogroup 23 . Two of the remainder were serogroup 9, and there was one isolate each of serotype 14 and serotype 17 . One isolate was untypable.

The MIC range and MIC90 of penicillin for the 216 cefotaxime-resistant pneumococci were $0.5-16 \mathrm{mg} / \mathrm{L}$ and $8 \mathrm{mg} / \mathrm{L}$ respectively. For cefotaxime, the MIC range was $2-32 \mathrm{mg} / \mathrm{L}$ and the MIC90 was $8 \mathrm{mg} / \mathrm{L}$. The

Table 1. Antibiotic resistance patterns of 216 cefotaxime-resistant pneumococci

\begin{tabular}{lc}
\hline Antibiotic resistance pattern & Number of isolates \\
\hline C P & 1 \\
C P & 1 \\
C P T & 1 \\
C P T/S & 1 \\
C P E T & 3 \\
C P E T & 1 \\
C P E T/S & 11 \\
C P Cm T & 6 \\
C P Cm E & 6 \\
C P Cm T T/S & 4 \\
C P Cm E T & 11 \\
C P E T T/S & 156 \\
C P Cm E T/S & 7 \\
C P Cm E T T/S & 7 \\
\hline
\end{tabular}

$\mathrm{C}$, cefotaxime $\mathrm{MIC} \geqslant 2 \mathrm{mg} / \mathrm{L}) ; \mathrm{P}$, penicillin $(\mathrm{MIC} \geqslant 2 \mathrm{mg} / \mathrm{L}) ; \mathrm{P}^{\mathrm{I}}$, penicillin (MIC $0.12-1 \mathrm{mg} / \mathrm{L}$ ); $\mathrm{T}$, tetracycline $(30 \mu \mathrm{g}$ disk $\leqslant 18 \mathrm{~mm}$ ); $\mathrm{T} / \mathrm{S}$, co-trimoxazole (trimethoprim/sulphamethoxazole $\mathrm{MIC} \geqslant 4$ / $76 \mathrm{mg} / \mathrm{L}$ ); E, erythromycin (MIC $\geqslant 1 \mathrm{mg} / \mathrm{L}$ ); $\mathrm{Cm}$, chloramphenicol $(30 \mu \mathrm{g}$ disk $\leqslant 20 \mathrm{~mm})$. antibiotic resistance patterns of the 216 isolates are shown in Table 1 . Most $(156 ; 72 \%)$ of the isolates exhibited a common resistance pattern: resistance to cefotaxime, penicillin, erythromycin, tetracycline and co-trimoxazole.

Among the 146 serogroup 19 isolates of S. pneumoniae, 112 were found to belong to serotype $19 \mathrm{~F}$ and one was untypable. The MIC range and MIC90 of cefotaxime for the 113 isolates were $4-32 \mathrm{mg} / \mathrm{L}$ and $16 \mathrm{mg} / \mathrm{L}$, respectively. Four different antibiotic resistance patterns were found among these isolates, but most $(106 ; 93.8 \%)$ showed resistance to cefotaxime, penicillin, erythromycin, tetracycline and co-trimoxazole. The age was known for 107 patients: 61 (57\%) were $\leqslant 15$ years, 17 (15.9\%) were aged 16-59 years, and $29(27.1 \%)$ were $\geqslant 60$ years. Most $(92.1 \%)$ of these pneumococci came from two cities: $62(54.9 \%)$ from Christchurch in the South Island and 42 (37.2\%) from Palmerston North in the North Island.

\section{DNA macro-restriction typing}

Forty-eight serotype 19F isolates of S. pneumoniae (47 referred in 1997-1998 and one referred in 1996) were selected for macro-restriction analysis. The MIC values $(\mathrm{mg} / \mathrm{L})$ of cefotaxime for these isolates were: 0.03 (1 isolate); 0.5 (2); 1 (10, including the 1996 isolate); 2 (3); and $\geqslant 4$ (32). The 32 isolates for which the MIC of cefotaxime was $\geqslant 4 \mathrm{mg} / \mathrm{L}$ were selected to represent a wide geographical area and various patterns of susceptibility.

Among the 48 serotype 19F isolates, 41 were found to belong to a common restriction type after digestion with SmaI. Forty exhibited an identical profile that was designated $\mathrm{S} 1$; one displayed a profile that differed by one band and was designated S1a (Table 2). Representative SmaI profiles of these isolates are shown in Fig. 1. The remaining seven isolates exhibited five distinct profiles and varied in their antibiotic resistance patterns (Table 2).

Of the 32 isolates of $S$. pneumoniae with high-level cefotaxime resistance (MIC $\geqslant 4 \mathrm{mg} / \mathrm{L}$ ), 31 exhibited profile S1. All 31 were resistant to erythromycin, tetracycline and co-trimoxazole; the MIC of penicillin for all 31 isolates was $\geqslant 2 \mathrm{mg} / \mathrm{L}$. For 27 isolates, the MIC of cefotaxime exceeded the MIC of penicillin. The isolate with profile S1a was susceptible to cotrimoxazole; the MIC of penicillin for this isolate was $0.5 \mathrm{mg} / \mathrm{L}$.

Fourteen $(43.8 \%)$ of the 32 isolates were referred from Christchurch, 12 (37.5\%) from Palmerston North and six from four other geographical areas. Two were isolated from invasive pneumococcal disease and the remainder from various sites.

The MIC of cefotaxime for nine serotype 19F isolates 
Table 2. Sma I profiles and resistance patterns of 48 serotype 19F S. pneumoniae isolates

\begin{tabular}{|c|c|c|c|c|}
\hline \multirow[b]{2}{*}{ Sma I profile } & \multirow[b]{2}{*}{$\mathrm{n}$} & \multicolumn{2}{|c|}{ MIC (mg/L) } & \multirow[b]{2}{*}{ Antibiotic resistance pattern } \\
\hline & & Cefotaxime & Penicillin & \\
\hline S1 & 1 & 0.5 & 4 & P E T T/S \\
\hline S1 & 6 & 1 & $2-4$ & $\mathrm{C}^{\mathrm{I}} \mathrm{P}$ E T T/S; $\mathrm{C}^{\mathrm{I}} \mathrm{P}$ E T \\
\hline S1 & 2 & 2 & 4 & C P E T T/S \\
\hline S1 & 23 & $4-8$ & $2-8$ & C P E T T/S \\
\hline S1 & 8 & $16-32$ & $4-8$ & C P E T T/S \\
\hline S1a & 1 & 16 & 0.5 & $\mathrm{CP}^{\mathrm{I}} \mathrm{E} \mathrm{T}$ \\
\hline S2 & 1 & 0.03 & 0.03 & - \\
\hline S3 & 2 & 1.0 & 2.0 & $\mathrm{C}^{\mathrm{I}} \mathrm{P}$ E T T/S; $\mathrm{C}^{\mathrm{I}} \mathrm{P}$ E $\mathrm{T}$ \\
\hline S4 & 1 & 1.0 & 4.0 & $\mathrm{C}^{\mathrm{I}} \mathrm{P} \mathrm{E} \mathrm{T} / \mathrm{S}$ \\
\hline S4 & 1 & 2.0 & 4.0 & C P E T/S \\
\hline S5 & 1 & 1.0 & 2.0 & $\mathrm{C}^{\mathrm{I}} \mathrm{P} \mathrm{Cm} \mathrm{E} \mathrm{T}$ \\
\hline S6 & 1 & 0.5 & 2.0 & $\mathrm{P} \mathrm{T} / \mathrm{S}$ \\
\hline
\end{tabular}

$\mathrm{P}$, penicillin (MIC $\geqslant 2 \mathrm{mg} / \mathrm{L}$ ); $\mathrm{P}^{\mathrm{I}}$, penicillin (MIC $0.12-1 \mathrm{mg} / \mathrm{L}$ ); $\mathrm{C}$ (cefotaxime $\mathrm{MIC} \geqslant 2 \mathrm{mg} / \mathrm{L}$ ); $\mathrm{C}^{\mathrm{I}}$, cefotaxime (MIC $\left.1 \mathrm{mg} / \mathrm{L}\right)$; E, erythromycin $(\mathrm{MIC} \geqslant 1 \mathrm{mg} / \mathrm{L}) ; \mathrm{T}$, tetracycline $(30 \mu \mathrm{g}$ disk $\leqslant 18 \mathrm{~mm}$ ); T/S, co-trimoxazole (trimethoprim/sulphamethoxazole $\mathrm{MIC} \geqslant 4 / 76 \mathrm{mg} / \mathrm{L}$ ); $\mathrm{Cm}$, chloramphenicol $(30 \mu \mathrm{g}$ disk $\leqslant 20 \mathrm{~mm})$.

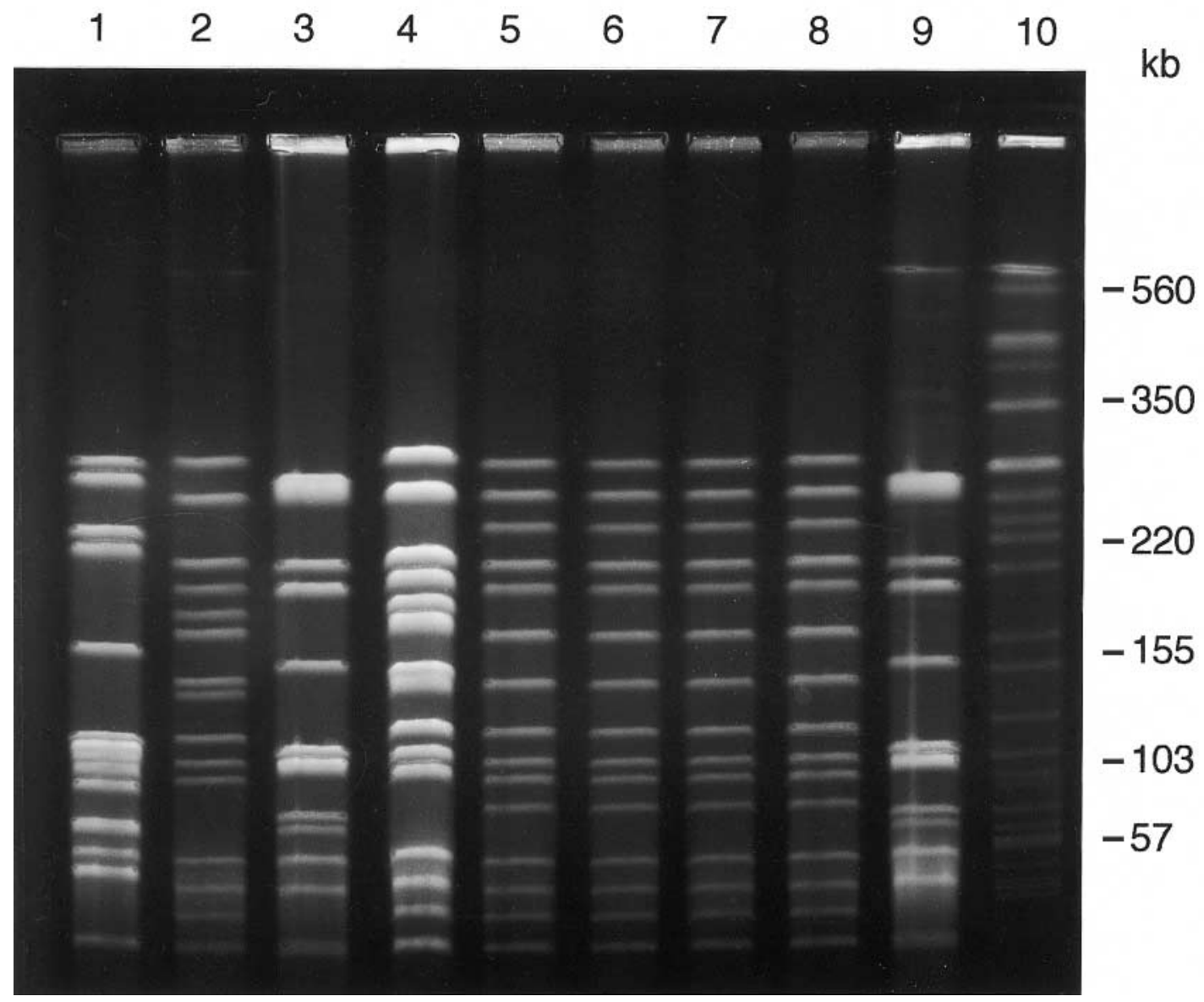

Fig. 1. Representative $S m a$ I profiles of serotype $19 \mathrm{~F}$ isolates. Lane 1, profile S2; 2, profile S3; 3, profile S4; 4, profile $\mathrm{S} 3 ;$ 5-8, profile S1; 9, profile S4; 10, mol. wt markers (Escherichia coli O157 strain G5244 digested with XbaI).

with profile S1 was $0.5-2 \mathrm{mg} / \mathrm{L}$. These isolates varied in their antibiotic resistance patterns (Table 2) and included a pneumococcus isolated in Christchurch in 1996.

\section{Discussion}

Extended-spectrum cephalosporins are widely used in the empiric treatment of severe infections caused by penicillin-resistant $S$. pneumoniae [7,8]. Pneumococci with high-level resistance to extended-spectrum cephalosporins have been reported from the USA [9] , UK [10] and Spain [11]. The spread of such strains would compromise the use of extended-spectrum cephalosporins in serious pneumococcal infections.

Before 1997, cefotaxime-resistant pneumococci were 
uncommon in New Zealand. In 1997, there was a sudden increase in the prevalence of cefotaximeresistant pneumococci including a large proportion with high-level cefotaxime resistance (MIC $\geqslant 4 \mathrm{mg} / \mathrm{L}$ ). Most were isolated in Christchurch and Palmerston North, but they were also found in other parts of New Zealand. Many of the isolates belonged to serotype 19F, were multiresistant and were unusual in that the MIC of cefotaxime was generally greater than that of penicillin.

DNA macro-restriction analysis revealed that all but one of 32 serotype $19 \mathrm{~F}$ pneumococci with high-level cefotaxime resistance exhibited indistinguishable Sma I restriction profiles. The other isolate differed by only one restriction fragment. This suggests that the isolates were genetically related and descended from a single ancestral strain. The SmaI restriction profile was shared with several isolates that were more susceptible to cefotaxime, suggesting that the strain with high-level cefotaxime resistance had evolved from a pre-existing strain. In contrast, isolates of $S$. pneumoniae from the USA that were resistant to extended-spectrum cephalosporins appear to have emerged on several occasions in different pneumococcal clones [9].

Further studies with multilocus sequence typing to investigate the relationship of the New Zealand strain to other multiresistant international clones are in progress.

I thank the staff of the hospital and community laboratories for submitting isolates and the staff of the Antibiotic Reference and Invasive Pathogens Laboratories, ESR, for technical assistance.
Surveillance of pneumococcal resistance is funded through a contract with the Ministry of Health, New Zealand.

\section{References}

1. Appelbaum PC. World-wide development of antibiotic resistance in pneumococci. Eur J Clin Microbiol 1987; 6: 367377.

2. Martin DR, Brett MS. Pneumococci causing invasive disease in New Zealand, 1987-94: serogroup and serotype coverage and antibiotic resistances. N Z Med J 1996; 109: 288-290.

3. Brett MS, Martin DR. A significant increase in antimicrobial resistance among pneumococci causing invasive disease in New Zealand. N Z Med J 1999; 112: 113-115.

4. National Committee for Clinical Laboratory Standards. Performance standards for antimicrobial susceptibility testing ninth informational supplement, NCCLS Document M100-S9 Pennsylvania: NCCLS, 1999

5. Brett MS, Short P, McLauchlin J. A small outbreak of listeriosis associated with smoked mussels. Int $J$ Food Microbiol 1998; 43: 223-229.

6. Lefévre JC, Bertrand MA, Faucon G. Molecular analysis by pulsed-field gel electrophoresis of penicillin-resistant Streptococcus pneumoniae from Toulouse, France. Eur $J$ Clin Microbiol Infect Dis 1995; 14: 491-497.

7. Friedland IR. Therapy of penicillin- and cephalosporin-resistant pneumococcal infections. Ann Med 1993; 25: 451-455.

8. Grimwood K, Collignon PJ, Currie BJ et al. Antibiotic management of pneumococcal infections in an era of increased resistance. J Paediatr Child Health 1997; 33: 287-295.

9. McDougal LK, Rasheed JK, Biddle JW, Tenover FC. Identification of multiple clones of extended-spectrum cephalosporin-resistant Streptococcus pneumoniae isolates in the United States. Antimicrob Agents Chemother 1995; 39: 22822288.

10. Johnson AP, Livermore DM, Woodford N, Quoraishi A, Freeman R. High-level beta-lactam resistance in strains of Streptococcus pneumoniae isolated in the UK. J Antimicrob Chemother 1998; 42: 115-116.

11. Ruiz J, Sempere M, Simarro E, Fenoll A. Description of two new isolates of Streptococcus pneumoniae in Spain that are highly resistant to cefotaxime. Antimicrob Agents Chemother 1998; 42: 2768-2769. 